\title{
Influence of Crystallization Additives on Morphology of Selected Benzoic Acids - a Molecular Dynamics (MD) Simulation Study
}
UNIVERSITY OF LATVIA
Aina Semjonova ${ }^{*}$, Agris Bērzinš̌
Laboratory of
Molecular Crystals
University of Latvia, Faculty of Chemistry, Riga, Latvia
*ainasemjonova@gmail.com
UNIVERSITY
OF LATVIA

\section{Introduction}

2 model substances were used in this study - 2,6-dimethoxybenzoic acid (2,6MeOBA) and 3-hydroxybenzoic acid (3OHBA), each having 2 polymorphic forms. Thermodynamically stable 3OHBA form I and unstable 2,6MeOBA form II contains carboxylic acid homodimers, whereas 3OHBA form II contains hydrogen bonded chains involving $\mathrm{O} 3$ atoms, and thermodynamically stabe 2,6MeOBA form I contains hydrogen bonded catemer synthon chains [1-6].

For the study 4-5 additives providing different intermolecular interaction possibilities were selected - urea 4-aminobenzoic acid (PABA), bis(2-hydroxyethyl)amino-tris(hydroxymethyl)methane (BIS-TRIS), trans-stilbene and 2-methyl-4-nitrobenzoic acid (2Me4NBA). For 2,6MeOBA all 5 additives were used, while for 3OHBA all but 2Me4NBA were used.

\section{Aim}
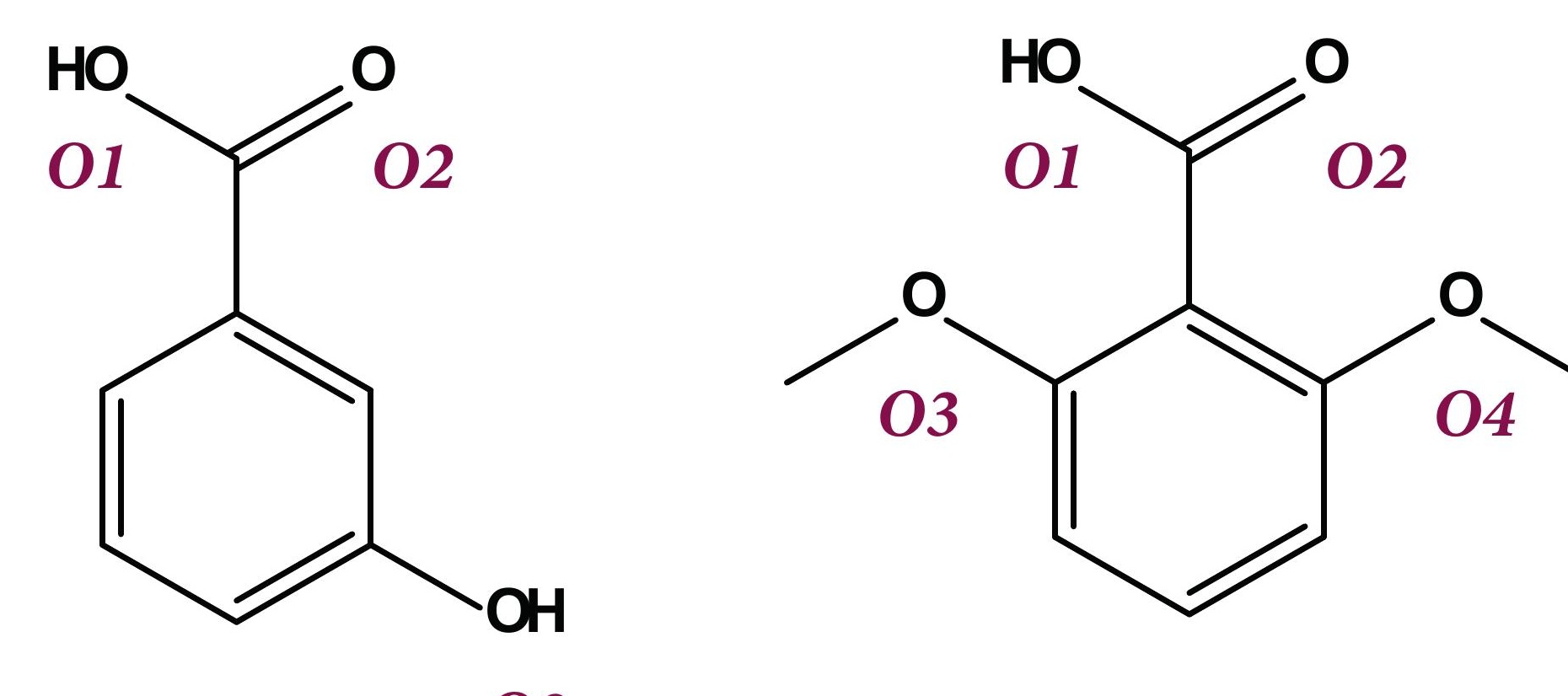

To evaluate which additives potentially can influence the crystal morphology and possibly also polymorph obtained in the crystallization by significantly changing the growth rate of crystal by adsorbing on the surface.

\section{Simulation boxes of model substances}

$2,6 \mathrm{MeOBA}$

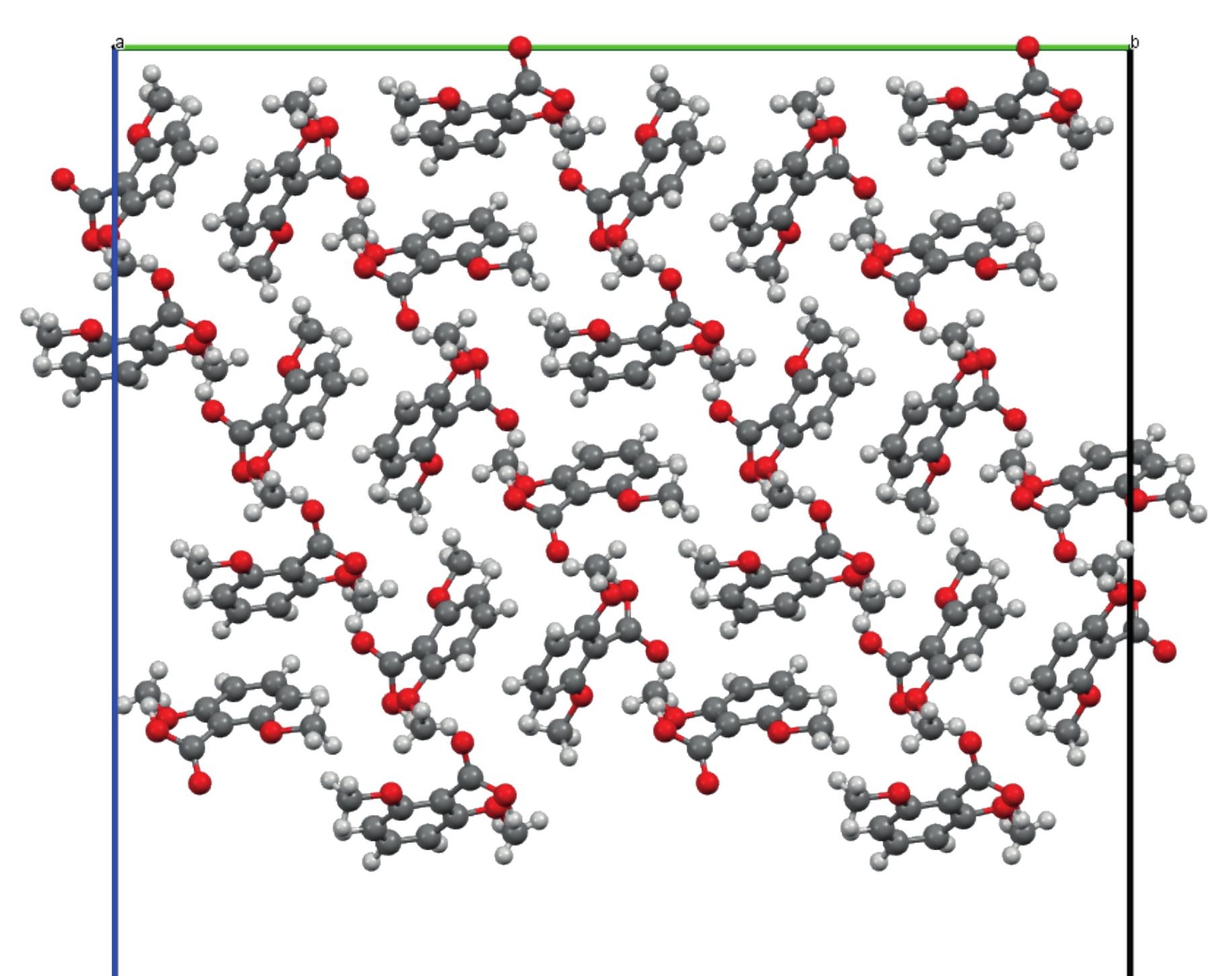

$\{011\}$

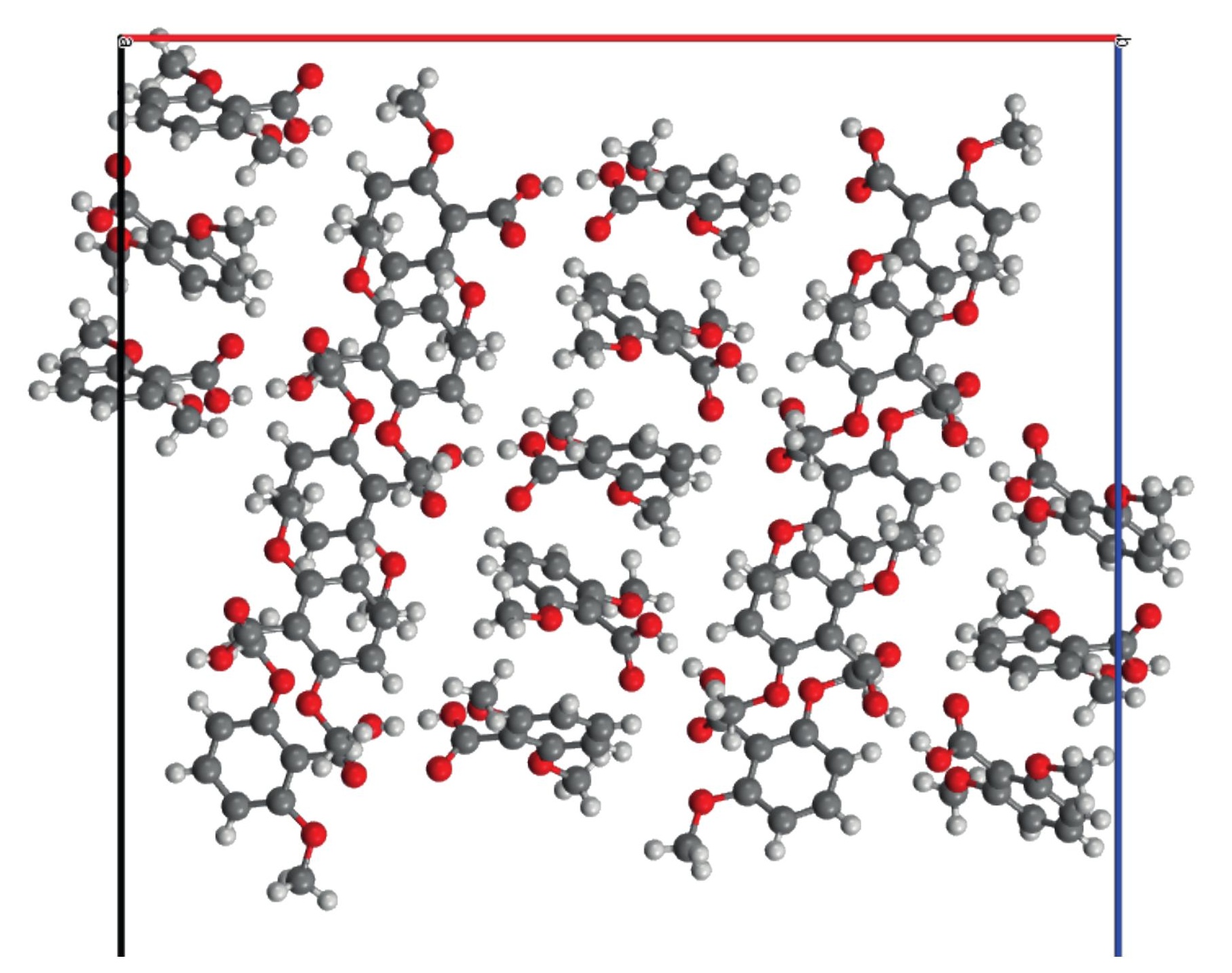

$\{101\}$

3OHBA

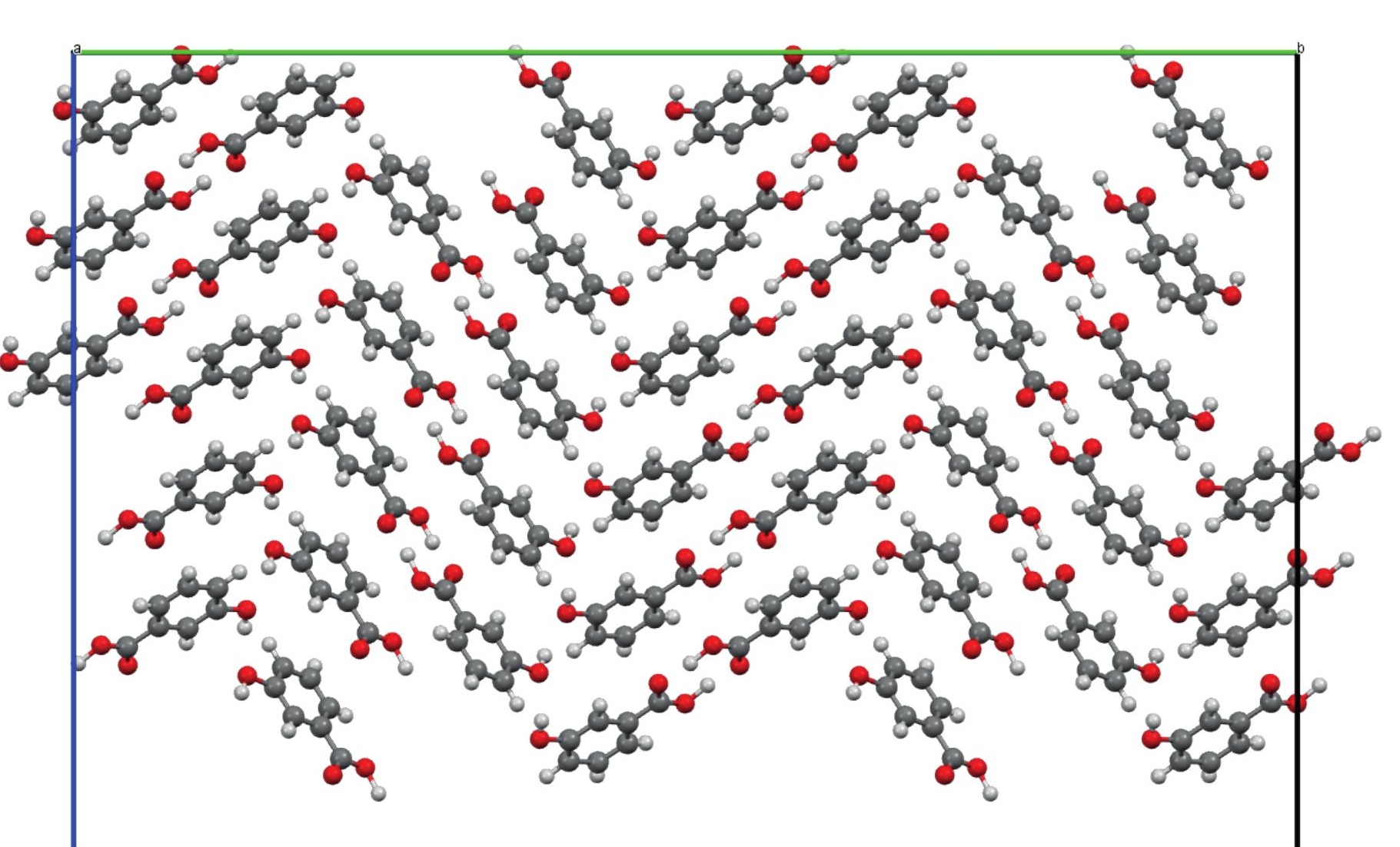

$\{011\}$

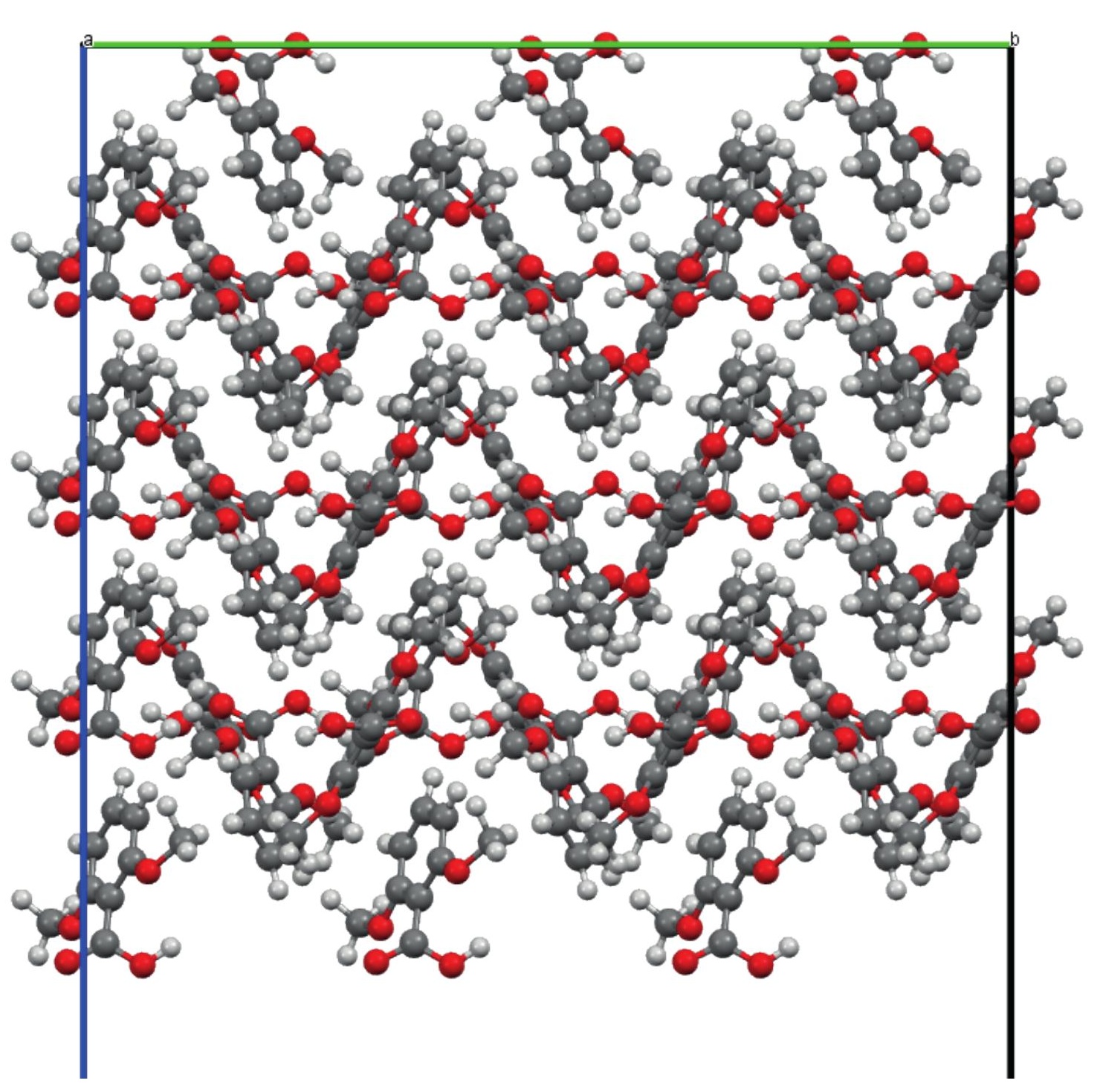

$\{101\}$

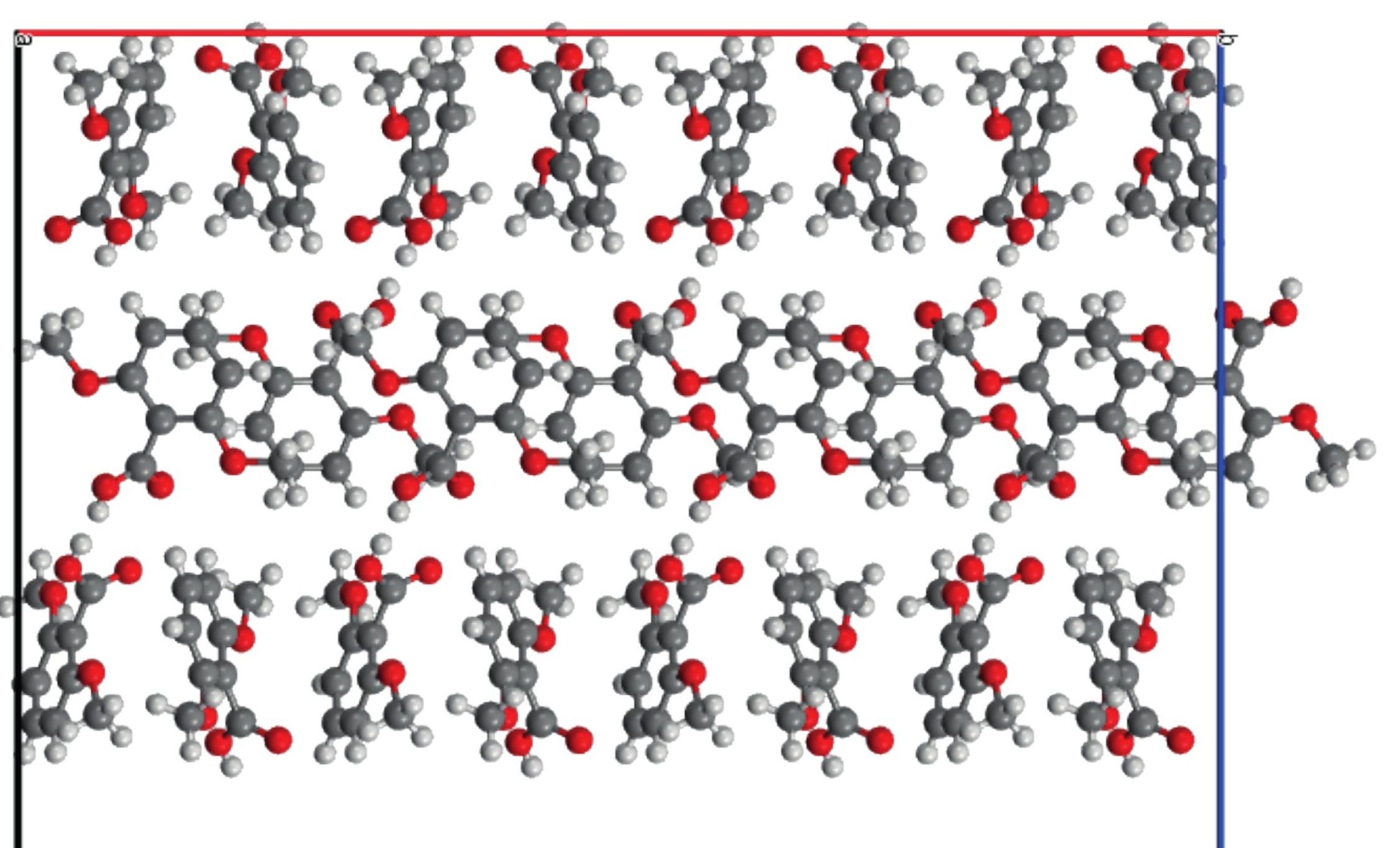

$\{004\}$

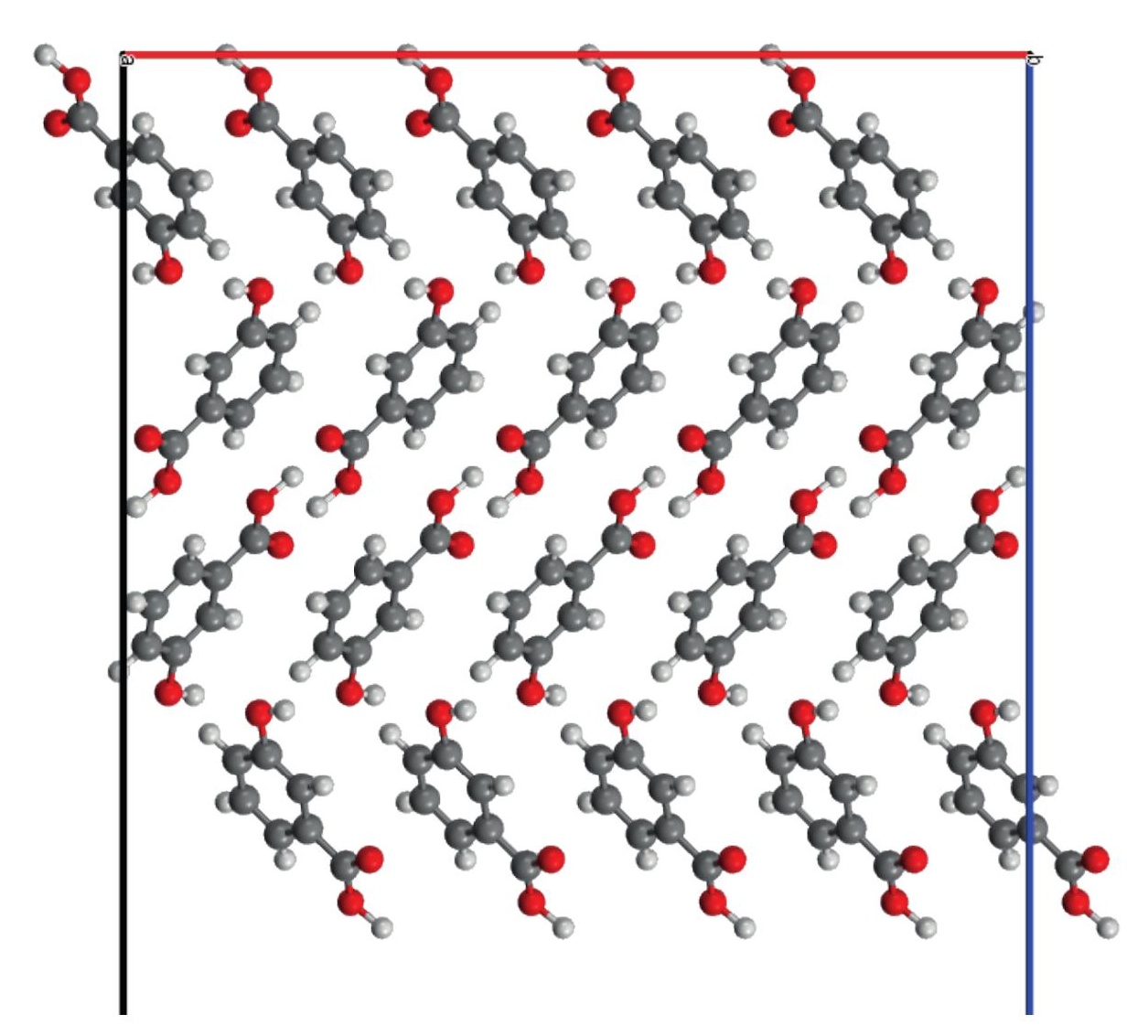

$\{020\}$

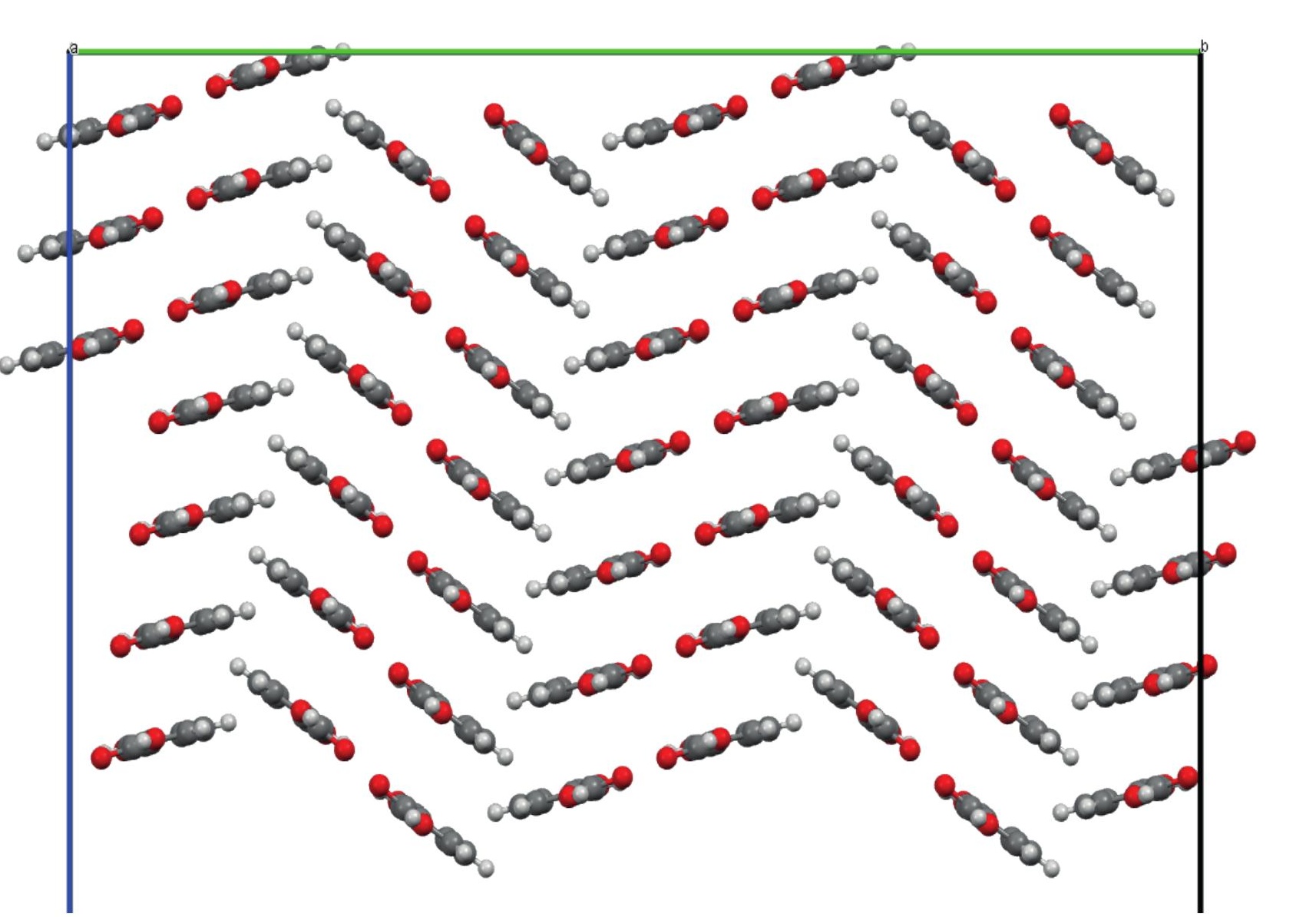

$\{101\}$

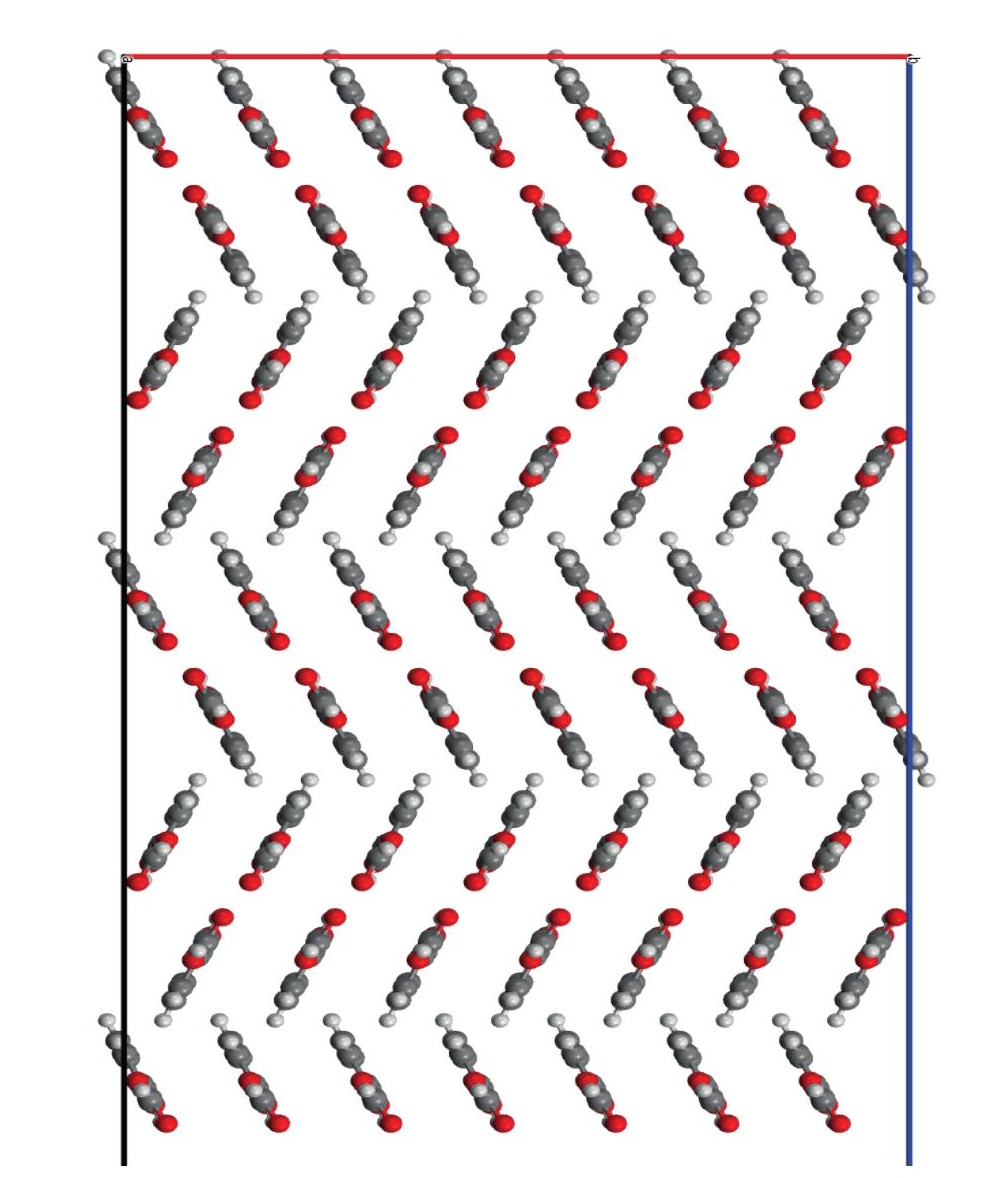

$\{200\}$

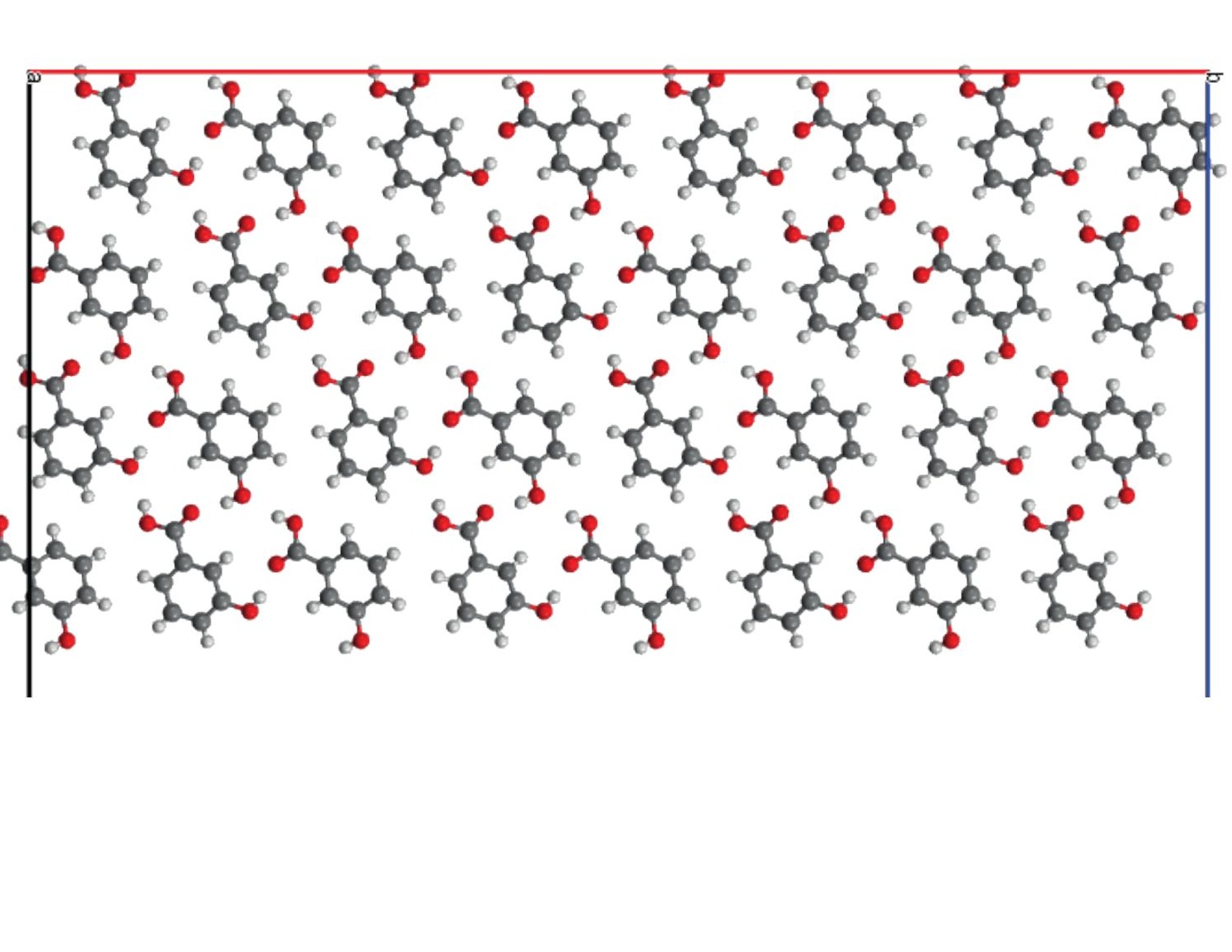

$\{201\}$

\section{References}

1. Clevers, S.; Simon, F.; Sanselme, M.; Dupray, V.; Coquerel, G. Cryst. Growth Des. 2013, 13

3697-3704

2. Nordstrom, F. L.; Rasmuson, A. C. Eur. J. Pharm. Sci. 2006, 28, 377-384.

3. Svärd, M.; Rasmuson, A. C. Cryst. Growth Des. 2013, 13, 1140-1152.

4. Portalone, G. Acta Cryst. 2009, E65, 0327-328.

5. Bryan, R. F.; White, B. H. Acta Cryst. 1982, B38, 1016-1018.

6. Portalone, G. Acta Cryst. 2011, E67, 03394-03395.

\section{Acknowledgment PostDoc}

This work was supported by the European Regional Development Fund, within the Project activity

1.1.1.2 "Post-doctoral Research Aid" (project no. 1.1.1.2/VIAA/1/16/195).

\section{Sorption of additives on 2,6IMeOBA surfaces}

The disintegration of the prepared crystal fragment was observed for form II in all the performed simulations.

BIS-TRIS and urea very similarly adsorbed on form I $\{011\}$ surface in 1,4-dioxane, although urea had slightly longer residence time and higher maximal probability to associate with crystal surface (adsorption propensity).

The best sorption on form I \{011\} surface in methanol showed trans-stilbene, but its resience time was rather low.

- Urea also showed the best adsorption propensity and residence time on form I $\{101\}$ surface in 1,4-dioxane.

For this surface in methanol the best adsorption propensity was again showed by trans-stibene, whereas the longest residence time was showed by urea.

\begin{tabular}{|c|c|c|c|c|c|c|c|c|}
\hline \multicolumn{2}{|c|}{$2,6 \mathrm{MeOBA}$} & \multirow[b]{2}{*}{ Solvent } & \multicolumn{3}{|c|}{ Associated molecules, \% } & \multicolumn{2}{|c|}{$(\mathrm{N}=18)$} & \multirow{2}{*}{$\begin{array}{l}\text { Additive with } \\
\text { the longest } \\
\text { residence time }\end{array}$} \\
\hline Form & Face & & BIS-TRIS & 2Me4NBA & PABA & stilbene* & urea & \\
\hline \multirow{4}{*}{ I } & & 1,4-dioxane & 55,6 & 22,2 & 44,4 & 38,9 & 55,6 & urea \\
\hline & $\{011\}$ & methanol & 27,8 & 22,2 & 27,8 & 50,0 & 22,2 & BIS-TRIS \\
\hline & & 1,4-dioxane & 38,9 & 16,7 & 27,8 & 38,9 & 61,1 & urea \\
\hline & $\{101\}$ & methanol & 27,8 & 16,7 & 22,2 & 72,2 & 22,2 & urea \\
\hline
\end{tabular}

"Measur

\section{Sorption of additives on $30 H B A$ surfaces}

- The disintegration of the prepared crystal fragments was observed for 3OHBA form I in methanol.

Urea showed the largest adsorption propensity and the longest residence time on form I \{011\}, form II $\{110\}$ and $\{201\}$ surfaces in 1,4-dioxane.

Urea showed the best and PABA the worst adsorption propensity on form I $\{011\}$ surface.

The best adsorption propensity and residence time on form II $\{110\}$ surface in methanol was observed for trans-stilbene.

BIS-TRIS showed the largest adsorption propensity and the longest residence time on form II $\{200\}$ surface.

The best sorbing additive on form II $\{200\}$ surface in methanol was urea, unlike on any other surface of 3OHBA.

- Form II $\{201\}$ surface was rather similar to the $\{200\}$ surface, but there was some differences in intermolecular interactions.

BIS-TRIS and urea shows the best association with crystal in 1,4-dioxane (both additives fully sorbs on the surface) with urea having slightly longer residence time (see Figure below). In methanol the results were similar to those in 1,4-dioxane, but the additive with the best adsorption propensity was BIS-TRIS even thought urea had the longest residence time.

Snapshot with atomic positions of crystal (purple) and urea (yellow) obtained at the end of MD simulation of $3 \mathrm{OHBA}$ form II \{201\} surface in 1,4-dioxane

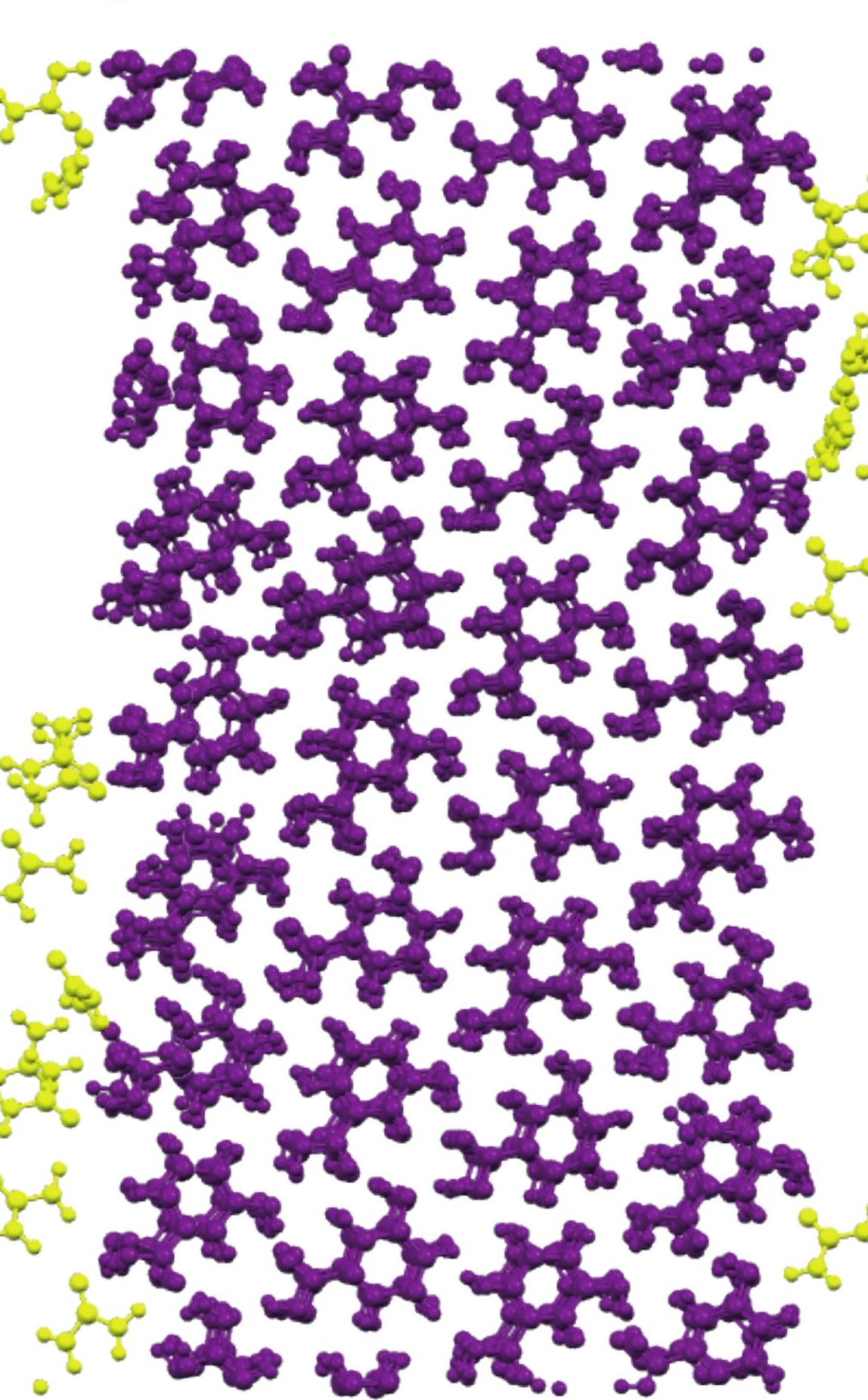

\begin{tabular}{|c|c|c|c|c|c|c|c|}
\hline \multicolumn{2}{|c|}{$3 \mathrm{OHBA}$} & \multirow[b]{2}{*}{ Solvent } & \multicolumn{4}{|c|}{ Associated molecules, \% } & \multirow{2}{*}{$\begin{array}{l}\text { Additive with the } \\
\text { longest residence } \\
\text { time }\end{array}$} \\
\hline Form & Face & & BIS-TRIS & PABA & $\begin{array}{c}\text { trans - } \\
\text { stilbene }^{*}\end{array}$ & urea & \\
\hline & $\{011\}$ & 1,4-dioxane & 72,2 & 44,4 & 61,1 & 88,9 & urea \\
\hline & $\{020\}$ & 1,4-dioxane & 50,0 & 55,6 & 16,7 & 22,2 & PABA \\
\hline & & 1,4-dioxane & 61,1 & 50,0 & 66,7 & 83,3 & urea \\
\hline & $\{110\}$ & methanol & 38,9 & 38,9 & 77,8 & 33,3 & $\begin{array}{l}\text { BIS-TRIS and } \\
\text { trans-stilbene }\end{array}$ \\
\hline & & 1,4-dioxane & 83,3 & 33,3 & 33,3 & 33,3 & BIS-TRIS \\
\hline & $\{200\}^{\#}$ & methanol & 50,0 & 33,3 & 33,3 & 58,3 & urea \\
\hline & & 1,4-dioxane & 100,0 & 77,8 & 22,2 & 100,0 & urea \\
\hline & $\{201\}$ & methanol & 61,1 & 44,4 & 27,8 & 50,0 & urea \\
\hline
\end{tabular}

"Measuring distance between mass centers in Plumed; for all others - determining number of hydrogen bonded additives in VMD. \#Simulation box contained 12 additive molecules, while in all other simulations it was 18.

the highest adsorption propensity

\section{Conclusions}

Growth of both explored surfaces of 2,6MeOBA form I could be best inhibited by urea in 1,4-dioxane, while by trans-stilbene in methanol. All the studied surfaces of form II disintegrated during the simulation, indicating the very low stability of this form.

- A different possible effect of urea and PABA on the morphology of 3OHBA form I was found. In 1,4-dioxane different adsorption propensity was observed for both additives. The growth of $\{011\}$ surface could be inhibited by urea, but growth of the $\{020\}$ surface by PABA.

The simulations showed that urea could not play a decisive role in discrimination of $3 \mathrm{OHBA}$ polymorphic forms, as it well sorbed on surfaces of both forms.

The simulations showed that trans-stilbene has the potential to inhibit the formation of $\{110\}$ surface of 3OHBA form II in methanol due to a strong $\pi-\pi$ interactions. Meanwhile, BIS-TRIS has a potential to inhibit growth of 3 OHBA form II $\{200\}$ and $\{201\}$ surfaces. Solvent has a notable effect on the sorption of additives. The sorption of the studied additives was notably different in 1,4-dioxane, but in methanol sorption of all additives was rather similar except for the trans-stilbene.

1,4-dioxane should be a better solvent for inhibition of growth of surfaces for which hydrogen bonds are the dominant type of

Among the studied additives urea showed the most complete sorption and the longest residence time on surfaces for both substances with exceptions of few specific planes. It can be added that such complete and irreversible adsorption on crystal could indicate on the ossibility of formation of a mixed phase (co-crystal) in the presence of these additives. 